\title{
Drug-Induced Hyperpigmentation: Review and Case Series
}

\author{
Rosa M. Giménez García, MD, and Sergio Carrasco Molina, MIR
}

Background: Hyperpigmentation is a common dermatologic problem that may have substantial impact on the patient, since it affects the appearance and quality of life, and may influence treatment adherence. There are few studies of drug-induced hyperpigmentation.

Methods: We studied drug-induced hyperpigmentation in patients attending an outpatient dermatology clinic in the Western Area of Valladolid (Spain) from August 1, 2017 to April 20, 2018.

Results: The incidence of drug-induced hyperpigmentation was $1.31 \%$ in patients attending a first dermatology consultation in the study period. Of the 16 patients, 8 were taking more than $1 \mathrm{drug}$. The most frequent drugs identified were nonsteroidal anti-inflammatory agents (25\%), antihypertensive agents (18.75\%), antimalarials (12.5\%), antibiotics, antineoplastic agents, psychoactive agents, simvastatin, allopurinol, amiodarone and mucolytic (6.25\% each). Hyperpigmentation was found in the mucosa in $25 \%$ of patients and in photograph-exposed areas in $37.5 \%$.

Discussion: Diagnosing drug-induced hyperpigmentation is a dermatologic challenge. A differential diagnosis with hyperpigmentation caused by endocrine and metabolic disorders, the most closely-related disorders to drug-induced hyperpigmentation, and with hyperpigmentation of idiopathic origin, should be conducted. Drug-induced hyperpigmentation is a relatively frequent reason for consultation, especially in polypharmacy patients. The sample may have been biased as many patients receiving treatments frequently associated with drug-induced hyperpigmentation, such as antineoplastic drugs, are diagnosed and treated by other specialties, such as oncologists.

Conclusion: Family physicians and specialists should consider drugs as a cause of hyperpigmentation to facilitate the correct diagnosis and treatment. (J Am Board Fam Med 2019;32:628-638.)

Keywords: Dermatology, Hyperpigmentation, Pharmacology, Practice Management, Spain

Hyperpigmentation is a common dermatologic problem that may have substantial impact on the patient, since it affects the appearance and quality of life. Hyperpigmentation is defined as the darkening of the skin's natural color, usually due to an increase in melanin deposition (hypermelanosis) in the epidermis or dermis, an increase in chromophores of nonmelanic origin (hyperchromia), or

This article was externally peer reviewed.

Submitted 26 July 2018; revised 24 February 2019; accepted 26 February 2019.

From the Department of Medicine, Dermatology and Toxicology, Faculty of Medicine, Valladolid, Spain (RMGG); Department of Dermatology, Hospital Universitario Rio Hortega, Valladolid, Spain (SCM).

Funding: none.

Conflict of interest: none declared.

Corresponding author: Rosa Gimenez Garcia, MD, Calle Carabela 115, Boecillo, 47151 Valladolid, Spain (E-Mail: rosagim@hotmail.com). to dermal deposition of endogenous or exogenous pigments such as hemosiderin, iron or heavy metals. Hyperpigmentation is a frequent reason for consultation, particularly in patients with darker skin. ${ }^{1}$

The color of human skin is mainly determined by 2 types of melanin; eumelanin and pheomelanin. Other important determinants of skin color are the number of blood capillaries it contains, the chromophores it may possess, such as carotenoids or lycopenes, and the collagen content of the dermis. ${ }^{2}$ The melanocytes, located in the epidermal basal layer, produce melanin by biosynthesis in the organelles called melanosomes, which are transported to the periphery and transferred, thanks to their dendritic extensions, from the melanocytes to the surrounding keratinocytes. Each melanocyte interacts with more or less 36 keratinocytes, in what is known as the melano-epidermal unit. ${ }^{2}$ 
Hypermelanosis in the epidermis is caused by an increase in melanin in the basal and suprabasal layer of the skin associated with a normal or elevated amount of melanocytes. Dermal hypermelanosis may be due to various mechanisms, such as the transfer of melanin from the epidermis to the dermis and its accumulation within the melanophages (pigmentary incontinence), and is commonly observed in inflammatory skin diseases affecting the basal layer and/or the dermal-epidermal junction. Another cause is dermal deposition of endogenous and exogenous pigments, such as hemosiderin or iron, or a local or systemic exposure to heavy metals (silver, gold, mercury). Metals such as iron can stimulate melanogenesis, as observed in patients with hemochromatosis. ${ }^{3}$

Drug-induced hyperpigmentation is estimated to account for $10 \%$ to $20 \%$ of cases of acquired hyperpigmentation, ${ }^{4}$ although these figures are probably highly speculative, as most cases are idiopathic, especially in elderly patients. The incidence of drug-induced hyperpigmentation varies according to the drug involved, ranging from isolated cases to $25 \%$ of patients receiving a treatment. ${ }^{5}$ Some drugs are associated with the development of hyperpigmentation of the skin or mucous membranes. $^{4-6}$

Clinically, the discoloration that appears on the skin is acquired and usually grows slowly and spreads insidiously, worsening over months or years after treatment initiation. Some topographical distributions are more characteristic of druginduced hyperpigmentation, such as areas exposed to the sun, and may include the mucous membranes, especially the oral and conjunctive membranes. Some characteristics of the distribution are very suggestive of specific drugs, such as the flagellated hyperpigmentation found when cytostatic treatments containing bleomycin are used. $^{7}$ The color acquired due to hyperpigmentation is not specific for drug-induced hyperpigmentation. However, drug-induced hyperpigmentation frequently presents as an unusual purple, with color tones such as red-yellow (clofazimine), ${ }^{8}$ or slate or blue-gray (psychotropic drugs, amiodarone, or metals). ${ }^{9,10}$

The diagnosis of hyperpigmentation is complicated due to the lack of direct evidence or inadequate information. Many elderly patients are receiving polypharmacy, making it more difficult to associate a pigment change with a specific drug, especially when the chronology between taking the drug and the onset of hyperpigmentation is unknown. The true incidence of drug-induced hyperpigmentation is very difficult to estimate because not all cases are recorded or reported for pharmacological study, and there are no large-scale prospective studies. The aims of this study were to review drug-induced hyperpigmentation, to carry out a study of patients with drug-induced hyperpigmentation attending a dermatology clinic for the first time, and to summarize the drugs known to cause hyperpigmentation. ${ }^{4,11}$

\section{Review}

\section{Antibiotics}

Tetracycline-induced hyperpigmentation is mainly due to minocycline and, less frequently, doxycycline or other first-generation tetracyclines. Minocycline-induced hyperpigmentation may occur in up to $15 \%$ of patients, especially those receiving prolonged treatment. Three types of hyperpigmentation induced by minocycline have been described: hyperpigmentation type 1 (blue-black hyperpigmentation in the site of previous inflammation or scarring) produced by pigment granules, probably iron chelates of minocycline; type 2 hyperpigmentation (gray-blue hyperpigmentation that affects normal skin, especially the legs) is probably due to minocycline metabolites in the skin; type 3 hyperpigmentation (dirty skin syndrome in areas exposed to the sun) in which microscopic studies finds higher amounts of melanin in the macrophages of the epidermis and dermis (Figure 1). This probably also applies to type-4 hyperpigmentation (hyperpigmentation of scars). ${ }^{11,12}$

Isolated cases of hyperpigmentation due to levofloxacin have been described, although in isolated cases and long-term treatment regimens, or due to polymyxin, an antibiotic used primarily for resistance against Gram-negative germs, or to tigecycline, a new glycylcycline antibiotic. ${ }^{13-16}$.

Overdoses of rifampicin may induce reddish hyperpigmentation, ${ }^{17}$ whereas isoniazid may sometimes produce purplish hyperpigmentation associated with pellagra. ${ }^{18}$ Dapsone may also trigger hyperpigmentation aggravated by the sun. ${ }^{19}$

\section{Antihypertensives}

Despite their widespread use, very few cases of hyperpigmentation induced by antihypertensive drugs have been reported. 
Figure 1. Minocycline induced facial hyperpygmentation.

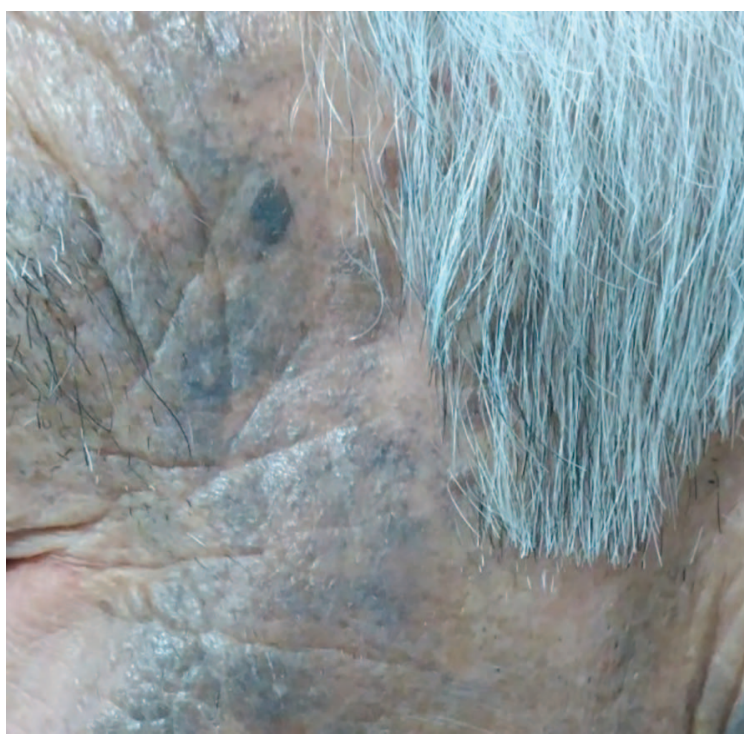

Angiotensin II receptor antagonists block the binding of angiotensin II to its receptor subtype 1 . Increased use of these antihypertensive agents has led to more visits to pharmacovigilance centers, but the only recorded cases of hyperpigmentation are 1 case due to telmisartan. ${ }^{20}$ There are some reported cases of hyperpigmentation induced by captopril, an angiotensin-converting enzyme inhibitor. ${ }^{21}$

Calcium channel blockers are first-line drugs for hypertension. Despite their widespread use, there are little data on the spectrum of adverse reactions they produce. There are several reports of photodistributed (reticulate or homogeneous) hyperpigmentation induced by diltiazem and amlodipine, ${ }^{22-25}$ and a recent case induced by lercanidipine ${ }^{26}$ (Figure 2).

Finally, $\beta$-blockers may produce cases of hyperpigmentation with a lichenoid appearance induced by nebivolol. ${ }^{27,28}$

\section{Anticonvulsants}

Anticonvulsants produce a high incidence of adverse drug reactions: hyperpigmentation has been reported associated with carbamazepine and lamotrigine. $^{29}$

Valproic acid is the most commonly prescribed antiepileptic worldwide and its effectiveness is demonstrated in adults and children with generalized or partial seizures and combined seizures. It is also prescribed for the management of schizophrenia and bipolar disorder, social phobias, and neu-
Figure 2. Hyperpigmentation due to lercanidipine.

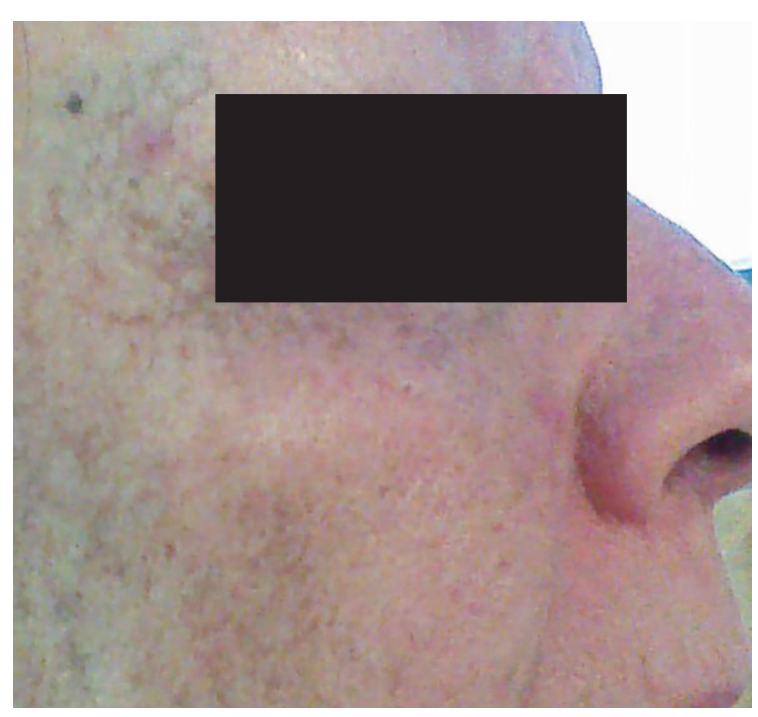

ropathic pain. Changes in hair color and curly hair have been described after use as have changes in nail pigmentation ${ }^{30,31}$ and 1 case of labial hyperpigmentation. ${ }^{32}$

Ten percent of patients taking phenytoin develop hyperpigmentation in the face and neck that resembles chloasma or acromelanosis and fades a few months after withdrawal of the drug. ${ }^{4,33}$

A fixed drug rash due to carbamazepine, appearing within the first 24 hours after the ingestion of the drug and leaving residual hyperpigmentation has been reported. ${ }^{34}$

\section{Psychoactive Agents}

The long-term use of phenothiazines or tricyclic antidepressants may induce hyperpigmentation, usually in areas exposed to the sun. Chlorpromazine is undoubtedly the drug most frequently implicated, causing violet or metallic gray purple pigmentation in areas exposed to the sun, mainly the face and limbs. ${ }^{35}$ The mucous membranes are preserved, but the pigmentation may affect the nails and the exposed parts of the eye. ${ }^{36}$ The other phenothiazines do not seem to show the same potential to produce hyperpigmentation, possibly due to structural differences that affect the melanin-binding sites. ${ }^{4}$

Tricyclic antidepressants, which are structurally related to phenothiazines, may induce hyperpigmentation ranging from blue to slate gray in areas exposed to the sun, but much less frequently than 
Figure 3. Clonazepam induced hyperpigmentation on extremities.

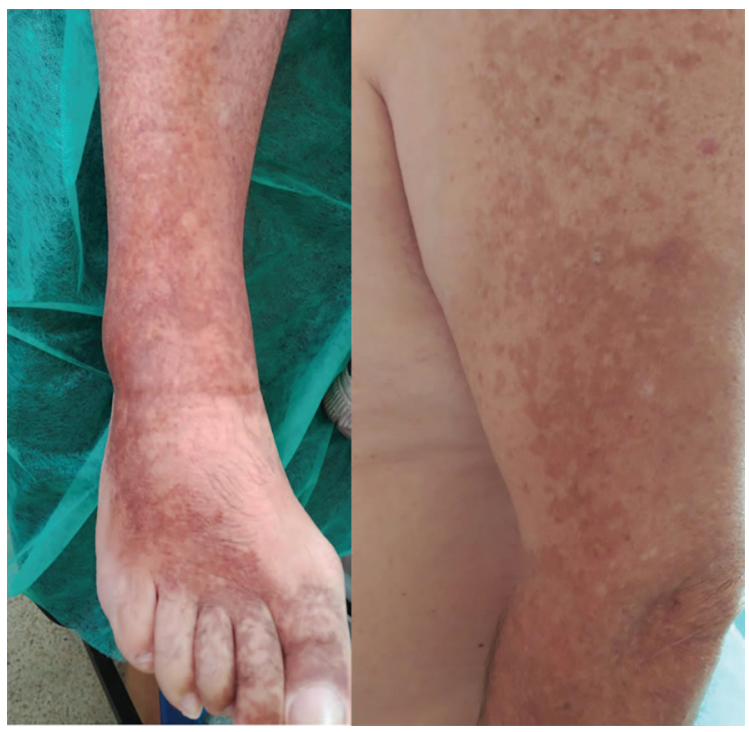

chlorpromazine. This adverse effect has been reported especially with imipramine. ${ }^{37}$ There are also reported cases of hyperpigmentation associated with amitriptyline. ${ }^{\text {' }}$

There are cases of hyperpigmentation caused by olanzapine, an atypical antipsychotic used both for schizophrenia and for depressive episodes associated with bipolar disorder, although cutaneous reactions are very rare. ${ }^{38,39}$ There are also reported cases caused by serotonin reuptake inhibitors ${ }^{40}$ and by levodopa and methyldopa. ${ }^{41}$ Finally, there are also cases of hyperpigmentation produced by benzodiazepines, such as clonazepam ${ }^{29}$ (Figure 3).

\section{Nonsteroidal Anti-Inflammatory Drugs}

Nonsteroidal anti-inflammatory drugs (NSAIDs) may trigger hyperpigmented lesions, usually in the form of a fixed drug rash. The pathophysiological mechanisms are not fully explained, but it is suggested that the NSAIDs could act as a hapten, binding to a protein bound to melanocytes, and producing a specific cytotoxic reaction directed at the melanocytes bound by the hapten. The drugs most frequently associated with this adverse reaction are paracetamol, salicylates, derivatives of oxicam, and ibuprofen ${ }^{42-45}$ (Figure 4).

\section{Antineoplastic Agents}

Several antineoplastic drug groups may cause hyperpigmentation. ${ }^{46}$ For example, within the alky-
Figure 4. Drug fixed eruption induced by NSAIDs.

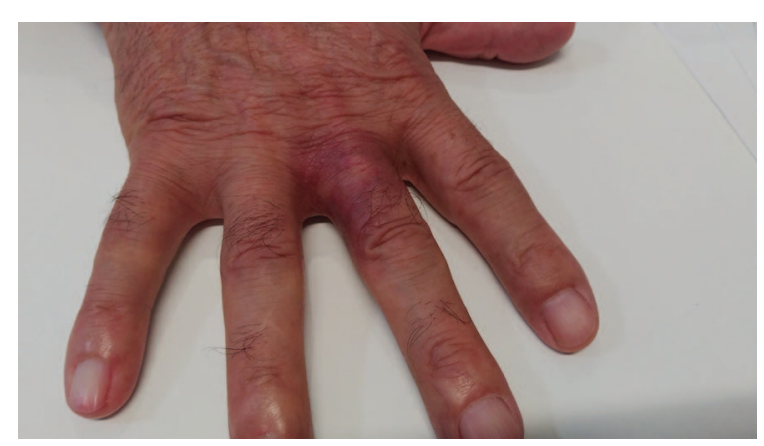

lating agents, cyclophosphamide, ifosfamide, and thiotepa have been identified as causes. Cyclophosphamide can cause hyperpigmented patches after the fourth week of treatment, which disappear 6 to 12 months after treatment cessation and may seem on the palms, soles, nails, teeth, and, rarely, on the gums. ${ }^{47}$ Ifosfamide hyperpigmentation occurs more frequently in the flexural areas, the hands, feet, and scrotum, and under occlusive bandages. This hyperpigmentation may occur after only 1 course or several months of therapy, and has a more unpredictable course than that of cyclophosphamide. ${ }^{48}$ Like ifosfamide, thiotepa can cause hyperpigmentation in occluded areas (it is believed to be excreted in sweat, and this may be the mechanism responsible for the hyperpigmentation). ${ }^{49}$ Other alkylating agents that cause hyperpigmentation are platinum metals, with cisplatin producing hyperpigmentation in $70 \%$ of patients, which may be localized or irregular, and affects the hair, nails, and oral mucosa. The risk increases with subsequent cisplatin treatments. ${ }^{50}$

Antimetabolites known to cause hyperpigmentation include 5-fluorouracil, capecitabine, and tegafur. Hyperpigmentation due to 5-fluorouracil may have a varied appearance and may gradually disappear over time and not recur in future exposures. ${ }^{51}$ Capecitabine and tegafur primarily cause acral hyperpigmentation in severe cases, but may also produce diffuse hyperpigmentation along the fold lines or in macular form in the palms. ${ }^{52,53}$

Among the antitumor antibiotics, bleomycin produces a characteristic, "flagellate-type" hyperpigmentation in $20 \%$ to $30 \%$ of patients, which may appear in the first 12 to 24 hours or up to 6 months later (Figure 5). It appears as linear erythematous lines with or without trauma. The lesions are self-limited by drug cessation and are 
Figure 5. Bleomycin-induced flagelated hyperpigmentation.

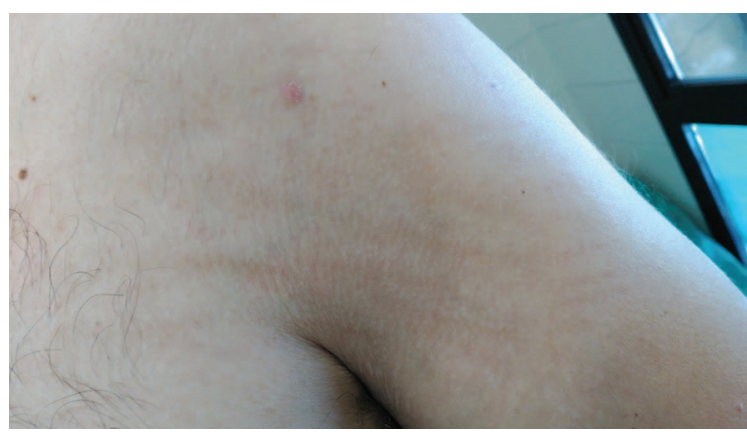

repeated in new exposures; recurrence is often more severe and widespread. ${ }^{7,54}$

\section{Heavy Metals}

Hyperpigmentation induced by heavy metals was frequent in the past, although reported cases have declined due to the decreasing use of these drugs as medicines. In fact, bismuth has been virtually abandoned and the indications for silver and gold salts have been drastically reduced in recent decades. The injection of iron salts, usually used in ferropenic anemia with iron malabsorption, frequently produces hyperpigmentation ranging from bluegray to brown. ${ }^{4}$

This group includes argyria, an infrequent bluegray hyperpigmentation of the skin and mucous membranes caused by prolonged exposure to silver. ${ }^{55}$

\section{Other Drugs}

Nail hyperpigmentation is one of the most frequent cutaneous adverse effects of antiretrovirals, and is mainly attributed to zidovudine. ${ }^{56}$ One case of hyperpigmentation due to tenofovir is reported. ${ }^{57}$ There are also reports of hyperpigmentation due to ribavirin and interferon $\alpha .^{58}$

With respect to monoclonal antibodies, cases of hyperpigmentation produced by imatinib, a tyrosine kinase inhibitor used in chronic myeloid leukemia, in addition to inhibiting c-kit and platelet derivated growth factor (PDGF), are reported. There is 1 reported case of diffuse hyperpigmentation $^{59}$ and many other cases of hyperpigmentation in the palate due to imatinib. ${ }^{60}$

Cutaneous hyperpigmentation caused by antimalarials is one of the most common adverse skin effects. ${ }^{61}$ Hyperpigmentation of the oral cavity is
Figure 6. Chloroquine induced hyperpigmentation.

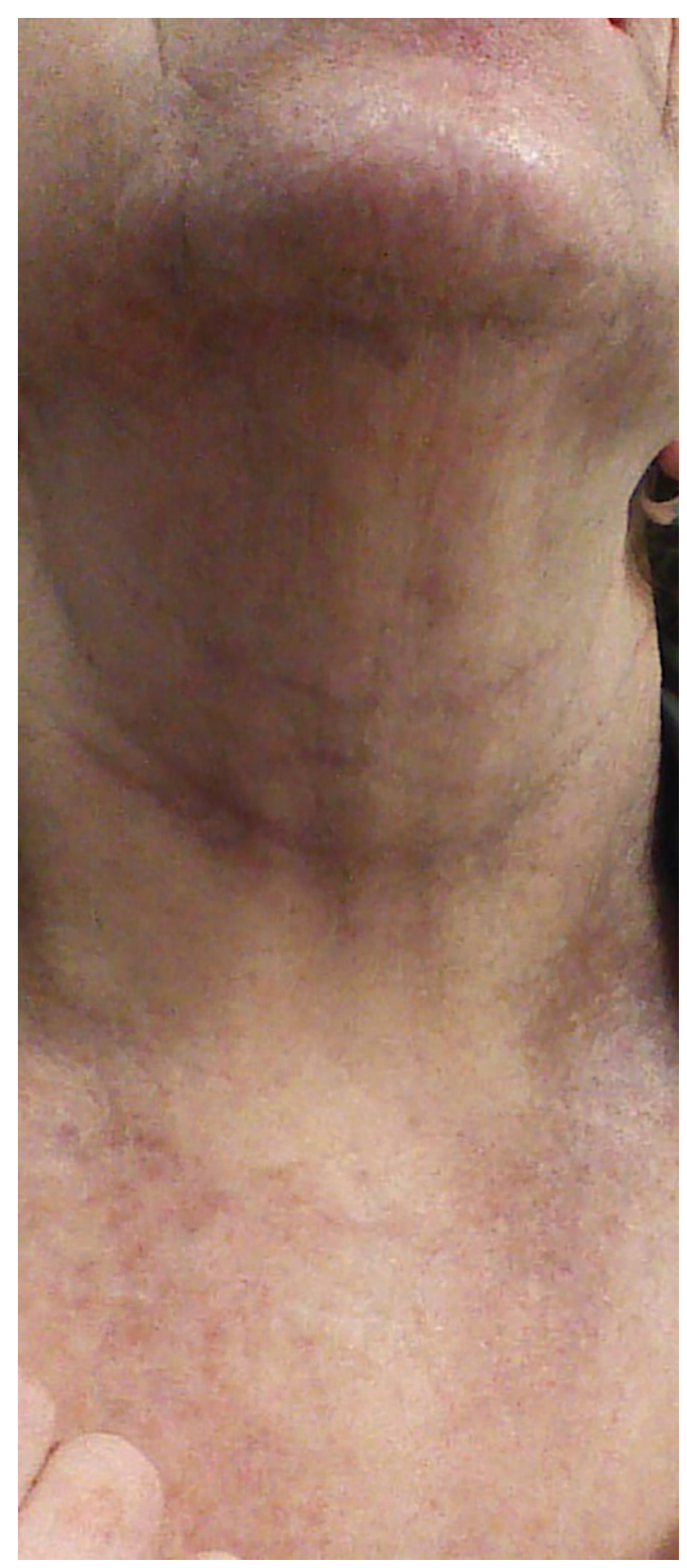

the most frequent finding, with several reported cases of hyperpigmentation of the oral mucosa due to hydroxychloroquine. ${ }^{62,63}$ There are also cases of hyperpigmentation of the nails or nose due to quinacrine or quinidine ${ }^{64}$ (Figure 6).

There are cases of carotenemia due to more widespread ingestion of oral carotene supplements in patients with ocular pathology. ${ }^{65}$ 
Figure 7. Amiodarone -induced hyperpigmentation on hands.

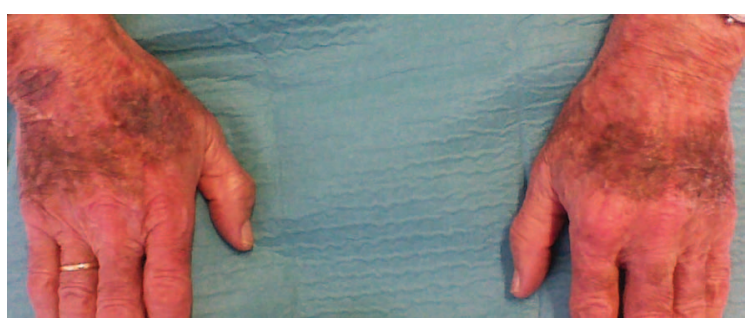

Cases of melasma and 1 of poorly defined irregular hyperpigmentation have been described, representing $66 \%$ of cases of dermatosis associated with oral contraceptives. ${ }^{66}$

Amiodarone, an antiarrhythmic agent used for ventricular and supraventricular arrhythmias causes blue-gray hyperpigmentation in areas exposed to the sun which is reversible, although it may take up to a year for complete resolution after treatment cessation $^{67,68}$ (Figure 7).

Table 1 shows a list of drugs that may cause drug-induced hyperpigmentation.

\section{Materials and Methods Setting}

The study was conducted in patients treated from August 1, 2017 to April 20, 2018 by outpatient dermatology clinics of the Rio Hortega University Hospital and the Arturo Eyries Specialty Center, both located in the western area of Valladolid. Patients were referred from primary health care according to the criteria of the family physician. The estimated population of the mixed urban/rural area is 257,940 .

Study inclusion criteria were attending a first dermatology consult, registered in the Valladolid West Health Area, a diagnosis of drug-induced hyperpigmentation made by the dermatologist, and confirmation of the resolution or improvement of hyperpigmentation after withdrawal of the suspected causal drug. Exclusion criteria were a second consult or review of previous dermatologic problem, or no resolution or improvement of hyperpigmentation after withdrawal of the suspected drug.

\section{Study Variables}

Through the clinical history and an interview we collected a series of variables in a closed protocol. The interview was face to face with the patient and, in the case of cognitive impairment, with the help of the caregiver. The variables collected were epidemiologic, triggering drug, main diagnosis, dermatologic variables, concomitant drugs, and history of allergy.

The 6-to-8-digit number of the medical record was taken as the reference. The number was masked by anonymizing it in a separate list

\section{Epidemiologic Variables: Sex, Age, in Years}

Dermatologic variables: reason for consultation, dermatologic pattern, location of hyperpigmentation, mucous membrane involvement, photosensitive distribution of hyperpigmentation

\section{Results}

Of the 1217 first consultations in our dermatology clinics between August 1, 2017 and April 20, 2018, 16 patients $(1.31 \%)$ were finally diagnosed as druginduced hyperpigmentation and were included in the study: $50 \%$ were male and the mean age was 63 years, standard deviation 16 years; range, 34 to 86 years.

Drug-induced hyperpigmentation was attributed to NSAIDs in 4 cases ( 2 due to ibuprofen + paracetamol, 1 to paracetamol and 1 to diclofenac; antibiotics (minocycline) in 1 case; antihypertensive agents in 3 cases ( 1 each due to lercanidipine, lisinopril with hydrochlorothiazide, and telmisartan with hydrochlorothiazide); antineoplastic agents (bleomycin) in 1 case; psychotropic drugs (clonazepam) in 1 case; other drugs in 6 cases ( 1 due to simvastatin, 2 to an antimalarial (chloroquine), 1 to an antigout agent (allopurinol), 1 to an antiarrhythmic agent (amiodarone) and 1 to a mucolytic (lysine carbocysteinate).

Of the 16 patients, 3 had a fixed drug rash. Eight patients were taking at least 1 other drug in addition to the causal drug, of which 3 were taking more than 1 additional drug. Four patients presented hyperpigmentation of the oral mucosa, 6 hyperpigmentation in photograph-exposed areas, 4 labial hyperpigmentation, 7 diffuse hyperpigmentation and 1 patient presented nail hyperpigmentation.

\section{Discussion}

We found an incidence of drug-induced hyperpigmentation of $1.31 \%$ in patients attending a dermatology clinic for the first time. The incidence found 


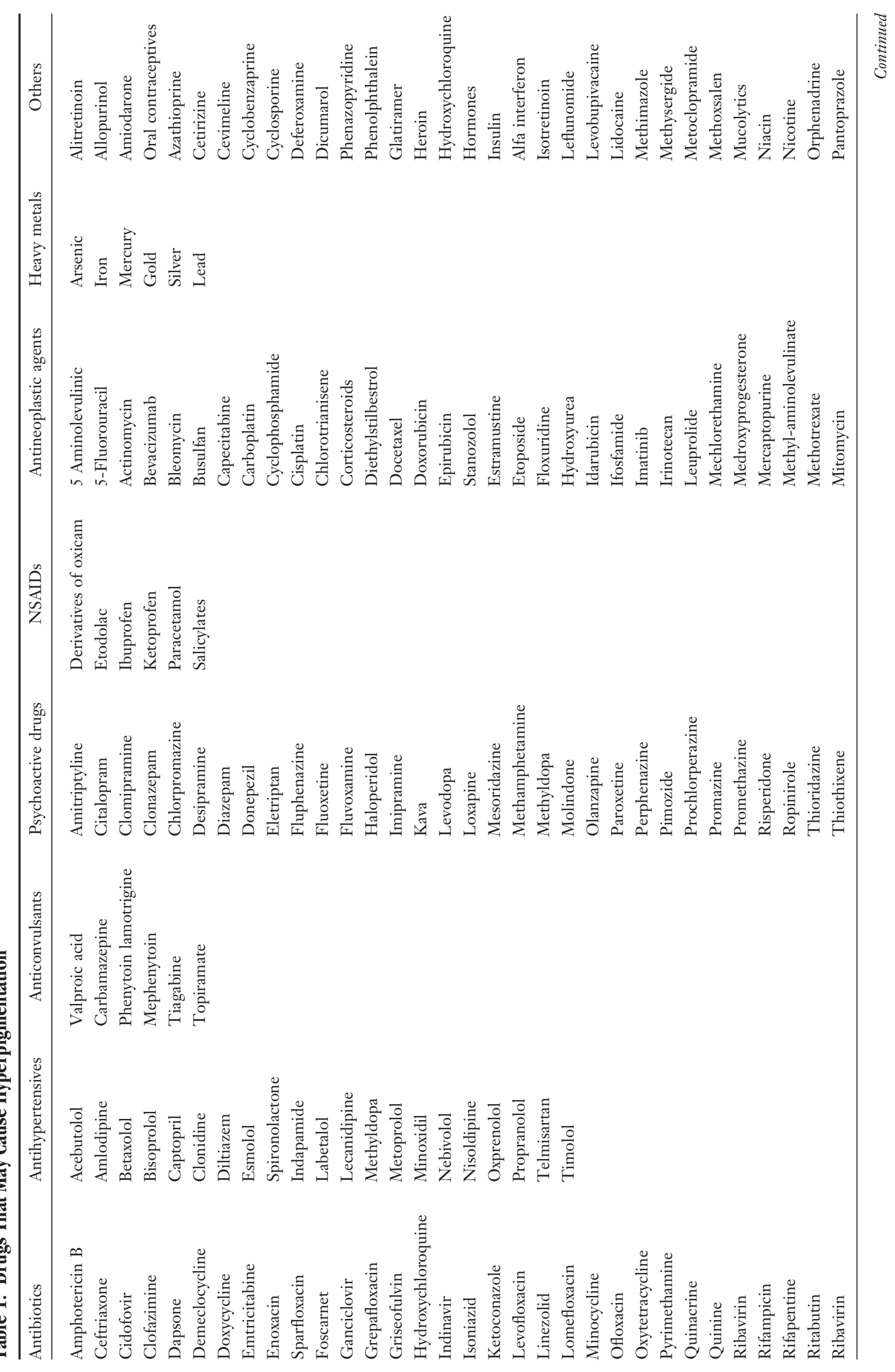




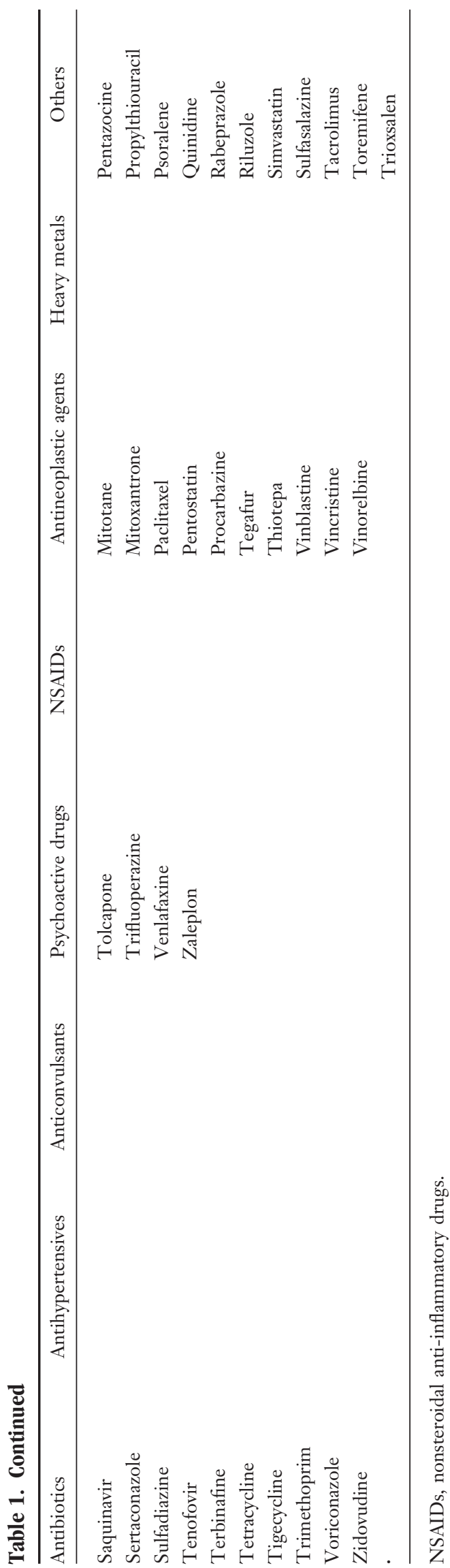

in other studies varies according to the drugs taken, but may reach $25 \%$ in patients receiving a specific drug. ${ }^{4}$ The incidence found was low, possibly because the sample was very small and not all patients presenting hyperpigmentation, especially oncological patients, are referred to a dermatology clinic.

Of the sixteen patients, 6 presented hyperpigmentation distributed in photograph-exposed areas, demonstrating the importance and effect of sunlight in this type of dyschromia. It is important to prevent exposure to ultraviolet radiation or to use adequate protection in patients taking drugs that increase the likelihood of causing hyperpigmentation. $^{5}$

Three patients presented a fixed drug rash. These are circumscribed, well defined and appear as pigmented macules after inflammatory lesions, and characteristically recur when the patient resumes taking the trigger drug. Many drugs and nonpharmacological preparations have been described associated with fixed drug exanthema, with NSAIDs being 1 of the most frequent triggers in our setting. ${ }^{4,69}$

Labial hyperpigmentation is associated with a wide variety of conditions in addition to drugs, including genodermatosis, inflammatory diseases, endocrine disorders, and neoplasms. Most drugs that cause labial hyperpigmentation are also associated with hyperpigmentation in other areas, such as the oral mucosa, skin, and nails. The drugs most associated with labial hyperpigmentation are minocycline, zidovudine, cyclophosphamide, doxorubicin, citalopram, levodopa, nicotine, and tacrolimus. $^{70}$

Four patients presented hyperpigmentation of the oral mucosa. Oral pigmentation caused by drugs occurs equally in all races and without differences in sex. The papillary gums are the most frequently affected, followed by the marginal gingiva and the buccal mucosa. It is not a medical problem, but patients usually complain about the blackish color of their gums. The most frequent causal drugs are antimalarials and minocycline. Antimalarials such as quinacrine, chloroquine, and hydroxychloroquine may induce intraoral pigmentation, described as slate gray. Although tetracyclines cause pigmentation of the teeth and bones, only minocycline causes pigmentation of the soft tissues. The pigmentation is brownish and occurs on the hard palate, gums, mucosa, and the tongue. ${ }^{71}$ 
Drugs may cause changes in hair pigmentation. There may be an increase in the lightness or greyness of some areas, darkening or even a complete change in hair color, which may include the scalp and all body hair. This is an infrequent adverse effect and, although not serious, negatively impacts the quality of life and may influence treatment adherence. ${ }^{72}$

We found no case of nail hyperpigmentation, but a large number of drugs of different classes may be responsible for changes in the nails, including, in addition to hyperpigmentation, reductions in the speed of growth, fragility, discoloration, transverse depressions, onycholysis, paronychia, and pyogenic granulomas of the periungual folds. Generally, these abnormalities are transient and disappear when treatment is withdrawn. ${ }^{73}$

Diagnosing drug-induced hyperpigmentation is a dermatologic challenge. An exhaustive history and examination are required to search for cutaneous and extracutaneous signs and symptoms. A differential diagnosis with hyperpigmentation caused by endocrine and metabolic disorders, the most closely-related disorders to drug-induced hyperpigmentation, and with hyperpigmentation of idiopathic origin, should be conducted. ${ }^{4}$

The treatment of hyperpigmentation is complicated. In addition, there are esthetic concerns. Therefore, drug-induced hyperpigmentation should be diagnosed and treated by dermatologists and any other specialty involved.

\section{Conclusions}

There are very few updated reviews of drug-induced hyperpigmentation. Drug-induced hyperpigmentation is a relatively frequent reason for consultation, especially in polypharmacy patients (50\% of our sample took more than 1 drug). $\mathrm{Pa}-$ tients taking some specific drugs should be advised to take precautions against the effects of sunlight. In our sample, NSAIDs and antihypertensive drugs were the most frequent causes of drug-induced hyperpigmentation.

To see this article online, please go to: http://jabfm.org/content/ 32/4/628.full.

\section{References}

1. Alexis AF, Sergay AB, Taylor SC. Common dermatologic disorders in skin of color: A comparative practice survey. Cutis 2007;80:387-394.

2. Bastonini E, Kovacs D, Picardo M. Skin pigmentation and pigmentary disorders: Focus on epider- mal/dermal cross-talk. Ann Dermatol 2016;28: 279-289.

3. Plensdorf S, Martinez J. Common pigmentation disorders. Am Fam Physician 2009;15;79:109-116.

4. Dereure O. Drug-induced skin pigmentation. Epidemiology, diagnosis and treatment. Am J Clin Dermatol 2001;2:253-262.

5. Moore DE. Drug-induced cutaneous photosensitivity: Incidence, mechanism, prevention and management. Drug Saf 2002;25:345-372.

6. Kang SJ, Davis SA, Feldman SR, et al. Dyschromia in skin of color. J Drugs Dermatol JDD 2014;13: 401-406.

7. Al-Khenaizan S, Al-Berouti B. Flagellate pigmentation: A unique adverse effect of bleomycin therapy. Eur J Dermatol EJD 2011;21:146.

8. Murashov MD, LaLone V, Rzeczycki PM, et al. The physicochemical basis of clofazimine-induced skin pigmentation. J Invest Dermatol 2018;138:697-703.

9. Eichenfield DZ, Cohen PR. Amitriptyline-induced cutaneous hyperpigmentation: Case report and review of psychotropic drug-associated mucocutaneous hyperpigmentation. Dermatol Online J 2016;17:22(2).

10. Weiss SR, Lim HW, Curtis G. Slate-gray pigmentation of sun-exposed skin induced by amiodarone. J Am Acad Dermatol 1984;11(5 Pt 1):898-900.

11. Krause W. Drug-induced hyperpigmentation: A systematic review. J Dtsch Dermatol Ges 2013;11:644651.

12. Hu SW, Robinson MR, Newlove T, et al. Minocycline-induced hyperpigmentation in multibacillary leprosy. Am J Dermatopathol 2012;34:e114-e118.

13. Knueppel RC, Rahimian J. Diffuse cutaneous hyperpigmentation due to tigecycline or polymyxin $\mathrm{B}$. Clin Infect Dis 2007;45:136-138.

14. Dinkel G, Kofler L, Sönnichsen K, et al. Elementspecific analysis of a hyperpigmentation caused by levofloxacin therapy. J Dtsch Dermatol Ges 2017;15: 949-951.

15. Garval E, Vuiblet V, Durlach A, et al. [Skin pigmentation induced by meropenem and levofloxacin]. Ann Dermatol Venereol 2017;144:793-798.

16. Lahiry S, Choudhury S, Mukherjee A, et al. Polymyxin B-induced diffuse cutaneous hyperpigmentation. J Clin Diagn Res 2017;11:FD01-FD02.

17. Holdiness MR. A review of the Redman syndrome and rifampicin overdosage. Med Toxicol Adverse Drug Exp 1989;4:444-451.

18. Bilgili SG, Karadag AS, Calka O, et al. Isoniazidinduced pellagra. Cutan Ocul Toxicol 2011;30:317319.

19. Bahadir S, Çobanoglu Ü, Çimsit G, et al. Erythema dyschromicum perstans: Response to dapsone therapy. Int J Dermatol 2004;43:220-222.

20. Giménez-García R. Hyperpigmentation induced by combination therapy with telmisartan-hydrochlorothiazide. J Clin Hypertens 2016;18:361-362. 
21. O’Neil MB, Balfe JW, Geary DF. Drug points: Captopril-related hyperpigmentation. Br Med J Clin Res Ed 1987;295:333.

22. Scherschun L, Lee MW, Lim HW. Diltiazem-associated photodistributed hyperpigmentation: A review of 4 cases. Arch Dermatol 2001;137:179-182.

23. Chawla A, Goyal S. Diltiazem-induced hyperpigmentation in an African American woman. J Am Acad Dermatol 2002;46:468-469.

24. Erbagci Z. Amlodipine associated hyperpigmentation. Saudi Med J 2004;25:103-105.

25. Kubo Y, Fukumoto D, Ishigami T, et al. Diltiazemassociated photodistributed hyperpigmentation: Report of two Japanese cases and published work review. J Dermatol 2010;37:807-811.

26. Slim R, Fathallah N, Larif S, et al. Drug reaction with eosinophilia and systemic symptoms due to lercanidipine. Indian J Dermatol Venereol Leprol 2016;82:324.

27. Bodmer M, Egger SS, Hohenstein E, et al. Lichenoid eruption associated with the use of nebivolol. Ann Pharmacother 2006;40:1688-1690.

28. Aslan AN, Güney MC, Akçay M, et al. Lichenoid type cutaneous hyperpigmentation induced by nebivolol. Turk Kardiyol Dern Ars 2017;45:268270.

29. Lapeere H, Boone B, De Schepper S, et al. Hypomelanoses and hypermelanoses. In: Fitzpatrick's dermatology in general medicine. 8th ed. New York, NY: McGraw-Hill; 2012, 804-826.

30. Buka R, Hille R, McCormack P. Yellow nail pigmentation following Depakote therapy. J Drugs Dermatol JDD 2003;2:545-547.

31. Gerstner T, Lipinski C, Longin E, et al. Valproateinduced change in hair color. J Am Acad Dermatol 2008;58(2 Suppl):S63-S64.

32. Giménez-García R, Carrasco-Molina S, ZambranoCenteno B. Valproic acid-induced hyperpigmentation. J Dermatol 2017;2:16-18.

33. Kanwar AJ, Jaswal R, Thami GP, et al. Acquired acromelanosis due to phenytoin. Dermatology 1997; 194:373-374.

34. Muñoz Estrada VF, Valenzuela Paz GA, Rochín Tolosa M. Estudio de 372 casos de eritema fijo pigmentario. Piel 2011;26:213-220.

35. Kass J, Hsu S. What is your diagnosis? Hyperpigmentation due to long-term chlorpromazine use. Cutis 2001;68:252,-260.

36. Molina-Ruiz AM, Pulpillo Á, Molina-Ruiz RM, et al. Chlorpromazine-induced severe skin pigmentation and corneal opacities in a patient with schizophrenia. Int J Dermatol 2016;55:909-912.

37. D’Agostino ML, Risser J, Robinson-Bostom L. Imipramine-induced hyperpigmentation: A case report and review of the literature. J Cutan Pathol 2009;36: $799-803$.
38. Jhirwal OP, Parsad D, Basu D. Skin hyperpigmentation induced by olanzapine, a novel antipsychotic agent. Int J Dermatol 2004;43:778-779.

39. Singh LK, Sahu M, Praharaj SK. Olanzapine-induced reversible pellagroid skin lesion. Curr Drug Saf 2015;10:251-253.

40. Cheng YC, Huang MC. Photosensitivity reaction associated with selective serotonin re-uptake inhibitors: Possible cross-sensitivity? Psychiatry Clin Neurosci 2014;68:244.

41. Hendrix JD, Greer KE. Cutaneous hyperpigmentation caused by systemic drugs. Int J Dermatol 1992; 31:458-466.

42. Linares T, Marcos C, Gavilan MJ, et al. Fixed drug eruption due to aceclofenac. Contact Dermatitis 2007;56:291-292.

43. Sánchez-Morillas L, Rojas Pérez-Ezquerra $P$, González Morales ML, et al. Fixed drug eruption due to ibuprofen with patch test positive on the residual lesion. Allergol Immunopathol (Madr) 2013;41:203204.

44. Bremec T, Demsar J, Luzar B, et al. Longstanding truncal hyperpigmented patches in a young man. Multiple fixed drug eruption caused by acetaminophen. Clin Exp Dermatol 2010;35:e56-e57.

45. Trujillo MJ, de Barrio M, Rodríguez A, et al. Piroxicam-induced photodermatitis. Cross-reactivity among oxicams. A case report. Allergol Immunopathol (Madr). 2001;1;29:133-136.

46. Reyes-Habito CM, Roh EK. Cutaneous reactions to chemotherapeutic drugs and targeted therapies for cancer: Part I. Conventional chemotherapeutic drugs. J Am Acad Dermatol 2014;71:203.e1203.e12; quiz 215-216.

47. Youssef M, Mokni S, Belhadjali H, et al. Cyclophosphamide-induced generalised reticulated skin pigmentation: a rare presentation. Int J Clin Pharm 2013;35:309-312.

48. Yule SM, Pearson AD, Craft AW. Ifosfamide-induced hyperpigmentation. Cancer 1994;73:240-241.

49. Horn TD, Beveridge RA, Egorin MJ, et al. Observations and proposed mechanism of $\mathrm{N}, \mathrm{N}^{\prime}, \mathrm{N}^{\prime \prime}$-triethylenethiophosphoramide (thiotepa)-induced hyperpigmentation. Arch Dermatol 1989;125:524527.

50. Al-Lamki Z, Pearson P, Jaffe N. Localized cisplatin hyperpigmentation induced by pressure. A case report. Cancer 1996 15;77:1578-1581.

51. Sanz-Sánchez T, Córdoba S, Jiménez-Ayala B, et al. 5-Fluorouracil-induced reticular hyperpigmentation]. Actas Dermosifiliogr 2008;99:573-574.

52. Vázquez-Bayo C, Rodríguez-Bujaldón AL, JiménezPuya R, et al. Hiperpigmentación secundaria a capecitabina. Actas Dermo-Sifiliográficas 2007;98:491493.

53. Teixeira V, Vieira R, Figueiredo A. Tegafur-induced acral hyperpigmentation. Dermatol Rep. 2011;3;3: e30. 
54. Pai GS, Vimala AM. Flagellate pigmentation and sclerodermoid changes: Cutaneous markers of bleomycin toxicity. Indian J Dermatol Venereol Leprol 1999;65:32-35.

55. Kubba A, Kubba R, Batrani M, et al. Argyria an unrecognized cause of cutaneous pigmentation in Indian patients: A case series and review of the literature. Indian J Dermatol Venereol Leprol 2013; 79:805-811.

56. Sharma A, Vora R, Modi M, et al. Adverse effects of antiretroviral treatment. Indian J Dermatol Venereol Leprol 2008;74:234-237.

57. Capelli L, Cuello C, E L, Garuti RA, et al. Hiperpigmentación cutáneo-mucosa y ungular secundaria a tenofovir. Arch Argent Dermatol 2013;63:23-26.

58. Marcoval J, Notario J, Martín C, et al. Pigmentación oral asociada al tratamiento con alfa-interferón $\mathrm{y}$ ribavirina para la hepatitis C. Actas Dermo-Sifiliográficas 2014;105:211-212.

59. Balasubramanian $\mathrm{P}$, Jagadeesan S, Thomas J. Imatinib-induced extensive hyperpigmentation in a case of chronic myeloid leukemia. Indian J Dermatol 2015;60:523.

60. Roeker LE, Wolanskyj AP. Imatinib-associated melanosis of the palate. Am J Hematol 2014;89:564.

61. Skare T, Ribeiro CF, Souza FHM, et al. Antimalarial cutaneous side effects: A study in 209 users. Cutan Ocul Toxicol 2011;30:45-49.

62. de Andrade BAB, Fonseca FP, Pires FR, et al. Hard palate hyperpigmentation secondary to chronic chloroquine therapy: Report of five cases. J Cutan Pathol 2013;40:833-838.

63. Jallouli M, Francès C, Piette JC, et al. Hydroxychloroquine-induced pigmentation in patients with sys- temic lupus erythematosus: A case-control study. JAMA Dermatol 2013;149:935-940.

64. Rosen T, Aponte C. Cutaneous hyperpigmentation due to chronic quinine ingestion. Cutis 2005;75: 114-116.

65. Takita Y, Ichimiya M, Hamamoto Y, Muto M. A case of carotenemia associated with ingestion of nutrient supplements. J Dermatol 2006;33:132-134.

66. Thomas P, Dalle E, Revillon B, et al. [Cutaneous effects in hormonal contraception]. NPN Med 1985; 5:19-24.

67. Ammoury A, Michaud S, Paul C, et al. Photodistribution of blue-gray hyperpigmentation after amiodarone treatment: Molecular characterization of amiodarone in the skin. Arch Dermatol 2008;144: 92-96.

68. Stähli BE, Schwab S. Amiodarone-induced skin hyperpigmentation. QJM Mon J Assoc Physicians 2011;104:723-724.

69. Flowers H, Brodell R, Brents M, Wyatt JP. Fixed drug eruptions: presentation, diagnosis, and management. South Med J 2014;107:724-727.

70. Vachiramon V, McMichael AJ. Approaches to the evaluation of lip hyperpigmentation. Int J Dermatol 2012;51:761-770.

71. Filitis DC, Graber EM. Minocycline-induced hyperpigmentation involving the oral mucosa after shortterm minocycline use. Cutis 2013;92:46-48.

72. Ricci F, De Simone C, Regno L et al. Drug-induced hair colour changes. Eur J Dermatol 2016;26:531536.

73. Piraccini BM, Alessandrini A. Drug-related nail disease. Clin Dermatol 2013;31:618-626. 